\title{
Tools for Sustainable Energy Engineering
}

\author{
Göran Wall \\ Department of Culture, Energy and Environment, Gotland University, Visby, Sweden \\ Tel: +46(0)498299131, Fax: +46(0)498299962
}

\begin{abstract}
Exergy concepts and exergy based methods offer an insight to the understanding of sustainable energy engineering. The utilization of energy and other resources by applying physical concept as exergy and exergy based methods and the value of these tools in the design and optimization are presented, in particular Life Cycle Exergy Analysis (LCEA). Optimization methods incorporating both exergy and economic conditions are also presented. This brings a new approach and insight to the engineering conditions for a sustainable development that is further elaborated. The importance of introducing this new knowledge into present engineering education and practices is argued for.
\end{abstract}

Keywords: Renewable energy, Energy Policy, Energy engineering, Sustainable development, Education.

\section{Nomenclature}

\begin{tabular}{|c|c|c|c|}
\hline$E$ & exergy ........... & $t$ & time......... \\
\hline$E_{\text {indirect }}$ & 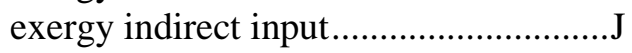 & $t_{0}$ & time when a project starts, e.g. the first \\
\hline$E_{\text {in }}$ & 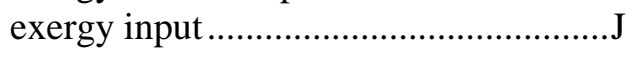 & & steps to build a power plant..................... \\
\hline$\dot{E}_{\text {in }}$ & 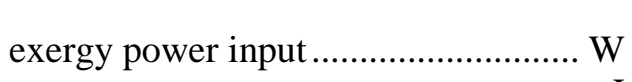 & $t_{\text {close }}$ & $\begin{array}{l}\text { time when an operation closes, e.g. a } \\
\text { power plant close down }\end{array}$ \\
\hline$E_{\text {out }}$ & exergy output & $t_{\text {life }}$ & time when a project finally closes, i.e. \\
\hline $\begin{array}{l}E_{\text {net,pr }} \\
E_{\text {pr }}\end{array}$ & $\begin{array}{l}\text { exergy net of product................................ } \\
\text { exergy of product.................................. }\end{array}$ & & $\begin{array}{l}\text { after complete restoration to original } \\
\text { state }\end{array}$ \\
\hline$E_{\mathrm{pr}}$ & exergy power of product..................... W & $t_{\text {payback }}$ & time when a payback situation is \\
\hline$E^{\mathrm{tot}}$ & total exergy ................................................ & & \\
\hline$E_{\mathrm{tr}}$ & transit exergy ........................................... & $\begin{array}{l}t_{\text {start }} \\
T\end{array}$ & me when an operation starts............. \\
\hline$E_{\text {waste }}$ & exergy of waste........................................ J & $T$ & $\ldots K$ \\
\hline & enthalpy ................................................ & $\begin{array}{l}I_{0} \\
I V\end{array}$ & environment ............ \\
\hline$i, j, k$, & 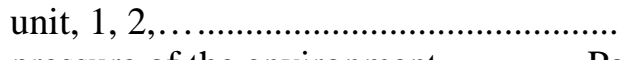 & U & internal energy ................................ \\
\hline $\begin{array}{l}P_{0} \\
Q\end{array}$ & pressure of the environment .............. Pa & & chemical potential of substance i in its \\
\hline $\begin{array}{l}Q \\
S\end{array}$ & 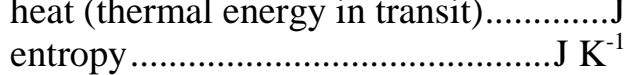 & $\mu_{i 0}$ & environmental state ....................... $\mathrm{J} \mathrm{mol}^{-1}$ \\
\hline
\end{tabular}

$S^{\text {tot }} \quad$ entropy of the total system, i.e. the system and the environment ............. $\mathrm{J} \mathrm{K}^{-1}$

\section{Introduction}

Exergy is a well established scientific concept suitable in the work towards sustainable development. Exergy accounting of the use of energy and material resources provides unique knowledge on how effective a process is in utilizing physical resources. This knowledge can identify areas in which technical and other improvements should be undertaken, and indicate the priorities, which should be assigned to conservation measures, efficiency improvements and optimizations. Thus, exergy concept and tools are essential to the creation of a new engineering paradigm towards sustainable development.

\section{Exergy}

The exergy concept originates from works of Carnot [1], Gibbs [2], Rant [3] and Tribus [4] and the history is well documented [5]. Exergy of a system is [6], [7] 


$$
E=U+P_{0} V-T_{0} S-\sum_{i} \mu_{i 0} n_{i}
$$

where $U, V, S$, and $n_{i}$ denote extensive parameters of the system (energy, volume, entropy, and the number of moles of different chemical materials $i$ ) and $P_{0}, T_{0}$, and $\mu_{i 0}$ are intensive parameters of the environment (pressure, temperature, and chemical potential). Analogously, the exergy of a flow can be written as:

$$
E=H-T_{0} S-\sum_{i} \mu_{i 0} n_{i}
$$

where $H$ is the enthalpy.

All processes involve the conversion and spending of exergy, thus high efficiency is of utmost importance. This implies that the exergy use is well managed and that effective tools are applied. Presently, an excellent online web tool for calculating exergy of chemical substance is also available [8].

Energy is always in balance, however, for real processes exergy is never in balance due to irreversibilities, i.e. exergy destruction that is related to the entropy production by

$$
E_{\text {in }}^{\text {tot }}-E_{\text {out }}^{\text {tot }}=T_{0} \Delta S^{\text {tot }}=\sum_{i}\left(E_{\text {in }}-E_{\text {out }}\right)_{i}>0
$$

where $\Delta S^{\text {tot }}$ is the total entropy increase, $E_{\text {in }}^{\text {tot }}$ is the total exergy input, $E_{\text {out }}^{\text {tot }}$ is the total exergy output, and $\left(E_{\mathrm{in}}-E_{\text {out }}\right)_{i}$ is the exergy destruction in sub process $i$.

The exergy loss, i.e. destruction and waste, indicates possible process improvements. In general "tackle the biggest loss first" approach is not always appropriate since every part of the system depends on each other, so that an improvement in one part may cause increased losses in other parts. As such, the total losses in the modified process may in fact be equal or even larger, than in the original process configuration. Also, the use of renewable and nonrenewable resources must be considered. Therefore, the problem needs a more careful approach.

\section{Exergy diagrams}

In engineering, flow diagrams are often used to describe the energy or exergy flows through a process. Fig. 1 shows a typical thermal power station, its main components and roughly the main energy and exergy flows of the plant. This diagram shows where the main energy and exergy losses occur in the process, and also whether exergy is destroyed from irreversibilities or whether it is emitted as waste to the environment. In the energy flow diagram energy is always conserved, the waste heat carries the largest amount of energy into the environment, far more than is carried by the exhaust gases. However, in the exergy flow diagram the temperature of the waste heat is close to ambient so the exergy becomes much less. The exergy of the exhaust gas and the waste heat are comparable.

Fig. 2 illustrates the energy and exergy flows of an oil furnace, an electric heater, an electric heat pump and a combined power and heat plant, i.e. a cogeneration plant. The produced heat is used for space heating. In the oil furnace the energy efficiency is assumed to be typically about $85 \%$, losses being due mainly to the hot exhaust gases. The exergy efficiency is very 
low, about $4 \%$, because the temperature difference is not utilized when the temperature is decreased, to a low of about $20^{\circ} \mathrm{C}$, as a comfortable indoor climate.

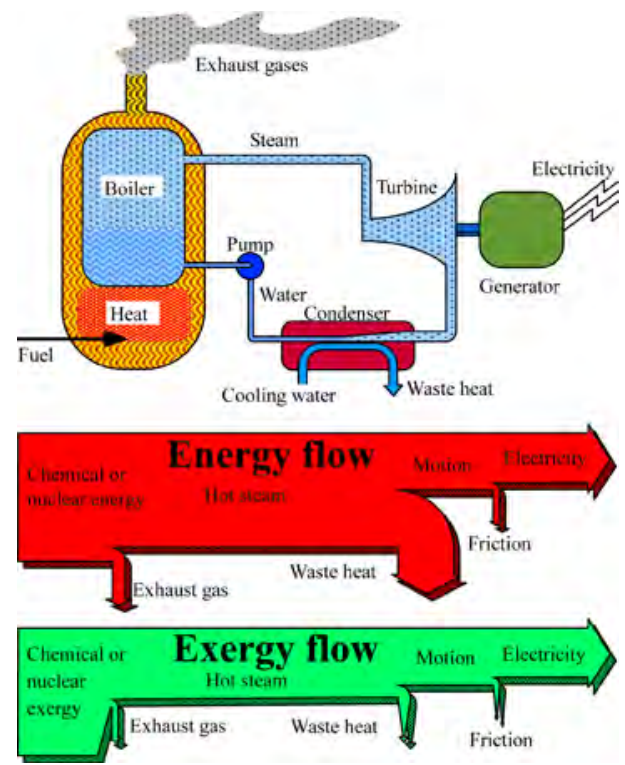

Fig. 1. Energy and exergy flow of a thermal power plant.

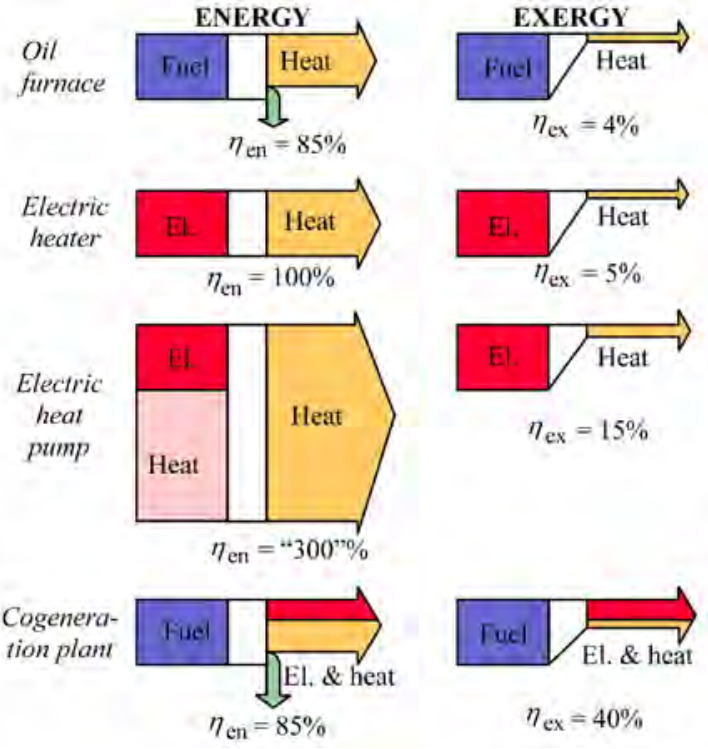

Fig. 2. Energy and exergy flows through typical some energy systems.

Electric heating by short-circuiting in electric resistors has an energy efficiency of $100 \%$, by definition of energy conservation. The energy efficiency of an electric heat pump is not limited to $100 \%$. If the heat originating from the environment is ignored in the calculation of the efficiency, the conversion of electrical energy into indoor heat can be well over $100 \%$, e.g. $300 \%$ as in Fig. 2. The exergy flow diagram of the heat pump looks quite different. The exergy efficiency for an electric heater is about 5\% and for the heat pump, $15 \%$.

In Fig. 1 the energy and exergy efficiencies are the same since both energy and exergy is almost equal for the inflow of fuels and the outflow of electricity. For a combined power and heat plant, i.e. a cogeneration plant (Fig. 2) the exergy efficiency is about the same as for a thermal power plant (Fig. 1). The main exergy loss occurs in the conversion of fuel into heat in the boiler. Since this conversion is practically the same in both the condensing and the combined power plants, the total exergy efficiency will be the same, i.e. about $40 \%$. However, it may be noted that the power that is instead converted into heat corresponds to a heat pump with a coefficient of performance (COP) of about 10. Thus, if there is a heating need a cogeneration plant is far superior to a condensing power plant. The maximum energy efficiency of an ideal conversion process may be over $100 \%$, depending on the definition of efficiency. The exergy efficiency, however, can never exceed $100 \%$.

\section{Exergy analysis}

To estimate the total exergy input that is used in a production process it is necessary to take all the different inflows of exergy to the process into account. This type of budgeting is often termed Exergy Analysis [6] \& [7], Exergy Process Analysis, see Fig. 3, or Cumulative Exergy Consumption [9], and focuses on a particular process or sequence of processes for making a specific final commodity or service. It evaluates the total exergy use by summing the contributions from all the individual inputs, in a more or less detailed description of the production chain. 
Environmentally oriented Life Cycle Analysis or Assessment (LCA) are common to analyze environmental problems associated with the production, use and disposal or recycling of products or product systems, see Fig. 4. Every product is assumed to be divided into these three "life processes", or as it is sometimes named "from cradle to grave".

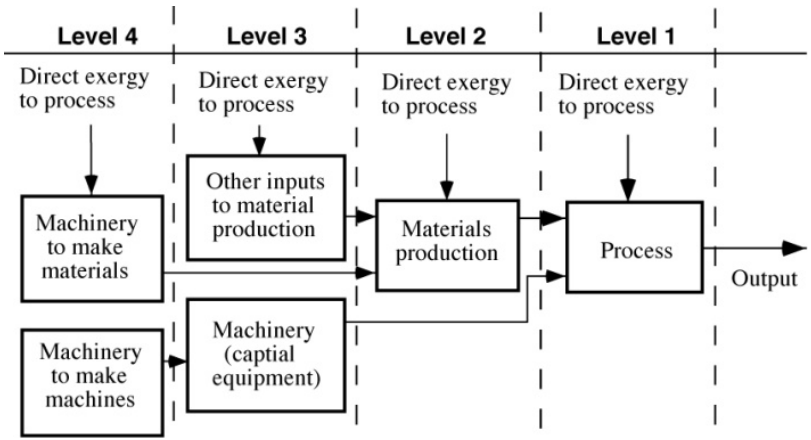

Fig. 3. Levels of an exergy process analysis.

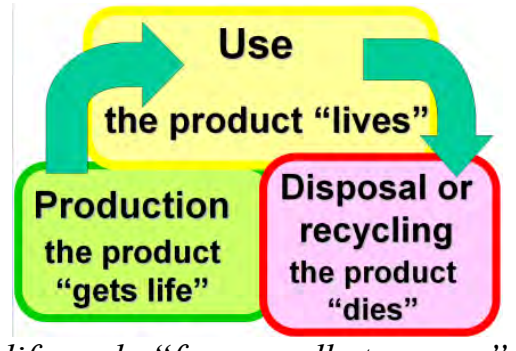

Fig. 4. The life cycle "from cradle to grave".

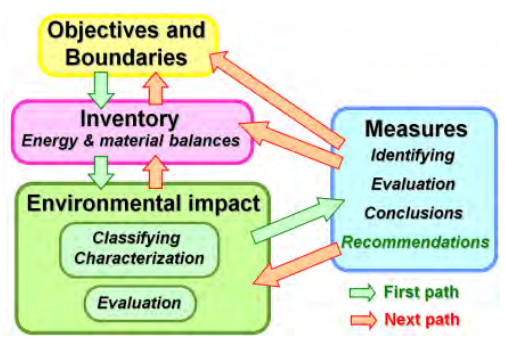

Fig. 5. Main steps of a LCA.

For every "life process" the total inflow and outflow of energy and material is computed, thus, LCA is similar to Exergy Analysis. In general Exergy Analysis and LCA have been developed separately even though they are strongly linked. This inventory of energy and material balances is then put into a framework as described in Fig. 5. Four stages in the LCA can be distinguished: (1) Objectives and boundaries, (2) Inventory, (3) Environmental impact, and (4) Measures. These four main parts of an LCA are indicated by boxes, and the procedure is shown by arrows. Green arrows show the basic steps and red arrows indicate suitable next steps, in order to further improve the analysis.

In LCA the environmental burdens are associated with a product, process, or activity by identifying and quantifying energy and materials used, and wastes released to the environment. Secondly one must assess the impact on the environment, of those energy and material uses and releases. Thus it is divided into several steps (Fig. 5).

The multidimensional approach of LCA causes large problems when it comes to comparing different substances, and general agreements are crucial. This problem is avoided if exergy is used as a common quantity, which is done in Life Cycle Exergy Analysis (LCEA) [10].

In this method we distinguish between renewable and non renewable resources. The total exergy use over time is also considered. These kinds of analyses are of importance in order to develop sustainable exergy supply systems in society. The exergy flow through a supply system, such as a power plant, usually consists of three separate stages over time (Fig. 6). At first, we have the construction stage where exergy is used to build a plant and put it into operation. During this time, $0 \leq t \leq t_{\text {start }}$, exergy is spent of which some is accumulated or stored in materials, e.g. in metals etc. Secondly we have the maintenance of the system during time 
of operation, and finally the clean up or destruction stage. These time periods are analogous to the three steps of the life cycle of a product in an LCA. The exergy input originating from non renewable resources used for construction, maintenance and clean up we call indirect exergy $E_{\text {indirect }}$. Indirect exergy input originating from renewable recourses are not accounted for. When a power plant is put into operation, it starts to deliver a product, e.g. electricity with exergy power $\dot{E}_{\mathrm{pr}}$, by converting the direct exergy power input $\dot{E}_{\mathrm{in}}$. In Fig. 6 the direct exergy is a non-renewable resource, e.g. fossil fuel and in Fig. 7 the direct exergy is a renewable resource, e.g. wind.

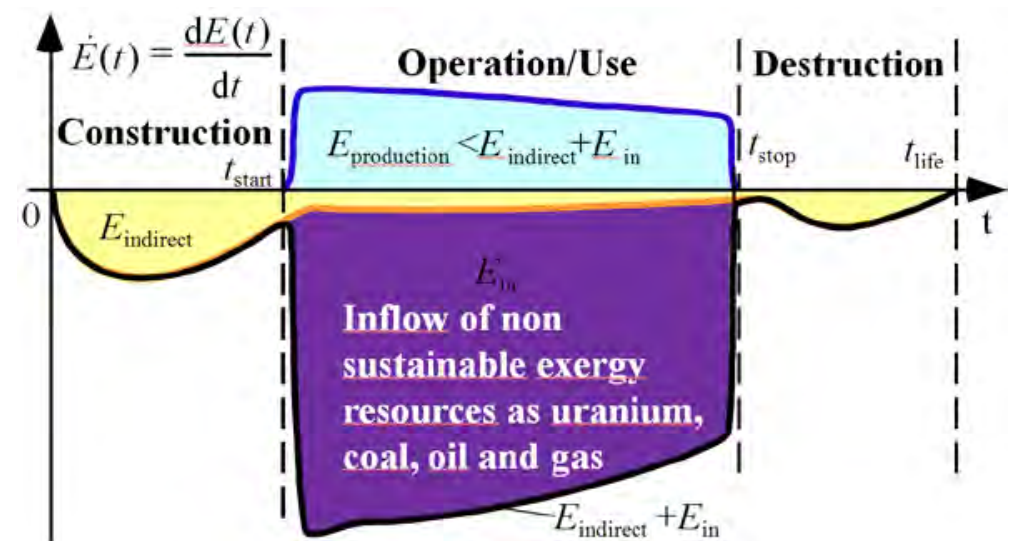

Fig. 6. LCEA of a fossil fueled power plant.

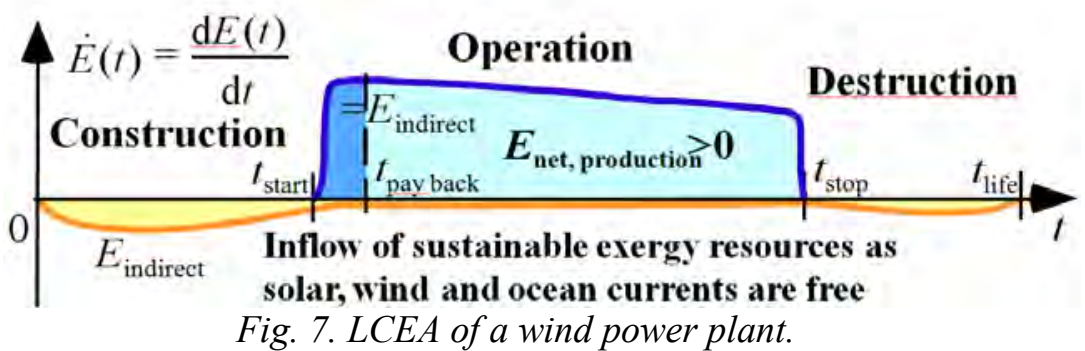

In the first case, the system is not sustainable, since we use exergy originating from a nonsustainable resource. We will never reach a situation where the total exergy input will be paid back, simply because the situation is powered by a depletion of resources, we have $E_{\text {pr }}<E_{\text {in }}+E_{\text {indirect. }}$. In the second case, instead, at time $t=t_{\text {payback }}$ the produced exergy that originates from a natural flow has compensated for the indirect exergy input, see Fig. 7, i.e.

$$
\int_{t_{\text {start }}}^{t_{\text {pay back }}} \dot{E}_{\mathrm{pr}}(t) d t=\int_{0}^{t_{\text {ire }}} \dot{E}_{\text {indirect }}(t) d t=E_{\text {indirect }}
$$

Since the exergy input originates from a renewable resource we may not account for it. By regarding renewable resources as free then after $t=t_{\text {payback }}$ there will be a net exergy output from the plant, which will continue until it is closed down, at $t=t_{\text {close }}$. Then, exergy has to be used to clean up and restore the environment, which accounts for the last part of the indirect exergy input, i.e., $E_{\text {indirect, }}$, which is already accounted for (Eq. 4). By considering the total life cycle of the plant the net produced exergy becomes $E_{\text {net,pr }}=E_{\mathrm{pr}}-E_{\text {indirect }}$. These areas representing exergies are indicated in Fig. 7. For modern wind power plants this time is less than one year [11]. Then the system has a net output of exergy until it is closed down, which for a wind power station may last for decades. Thus, these diagrams could be used to show if a power supply system is sustainable. 
LCEA is very important in the design of sustainable systems, especially in the design of renewable energy systems. Assume a solar panel, made of mainly aluminum and glass that is used for the production of hot water for household use, i.e. about $60^{\circ} \mathrm{C}$. Then, it is not obvious that the exergy being spent in the production of this unit ever will be paid back during its use, i.e., it might be a misuse of resources rather than a sustainable resource use. The production of aluminum and glass require a lot of exergy as electricity and high temperature heat or several hundred degrees Celsius, whereas the solar panel delivers small amounts of exergy as low temperature heat. LCEA must therefore be carried out as a natural part of the design of renewable energy systems in order to certify a sustainable resource use. Another case to investigate is the production of biofuels in order to replace fossil fuels in the transport sector. This may not necessarily be sustainable since the production process uses a large amount of fossil fuels, directly for machinery or indirectly as fertilizers, irrigation and pesticides. Thus, it may well turn out to be better to use the fossil fuels in the transport sector directly instead. This will be well described by a LCEA.

Sustainable engineering could be defined as the use of renewable resources in such a way that the input of non-renewable resources will be paid back during its life time, i.e. $E_{\mathrm{pr}}>E_{\mathrm{in}}+E_{\text {indirect }}$. In order to be truly sustainable the used non-renewable resources must also be completely restored or, even better, not used at all. Thus, by using LCEA and distinguishing between renewable and non-renewable resources we have an operational method to define sustainable engineering.

LCEA diagrams are of particular importance in the planning of large scale renewable energy systems of multiple plants. Initially, this system will consume most of its supply within its own constructions phase. However, some time after completion it will deliver at full capacity. Thus, the energy supply over time is heavily affected by internal system dynamics.

\section{Exergy and economics}

Exergy measures the physical value of an energy resource. Thus, it relates to the economic value, which reflects its usefulness. This makes exergy a valuable energy policy tool.

In order to encourage the use of sustainable resources and to improve resource use, an exergy tax could be introduced. The use of non-renewable resources and its waste should be taxed by the amount of exergy it accounts for, since this is related to depletion of resources and an environmental impact. In addition to this, toxicity and other indirect environmental effects must also be considered. In the case of irreversible environmental damage, a tax is not suitable, instead restrictions must be considered. Eventually, this should also be the case for the depletion of assets from future generations. At least it indicates a moral dilemma.

A system could be regarded as a part of two different environments, the physical and the economic environment. The physical environment is described by pressure $P_{0}$, temperature $T_{0}$, and a set of chemical potentials $\mu_{i 0}$ of the appropriate substances $i$, and the economic environment by a set of reference prices of goods and interest rates. These two environments are connected by cost relations, i.e. cost as a function of physical quantities (Fig. 8).

With the system embedded in the physical environment, for each component there are mass and energy balances needed to define the performance of the system. In addition, these balances describe the physical behavior of the system. 
If the cost relations are known, then the physical and economic environments could be linked. The cost equations can sometimes be simplified to a scale effect, times a penalty of intensity. Then the system of lowest cost, which is physically feasible, can be found. Usually the maintenance and capital costs of the equipment are not linear functions, so in many cases these costs have more complex forms. If, by some reason, it is not possible to optimize the system, then at least cost could be linked to exergy by assuming a price of exergy. This method is called Exergy Economy Accounting (EEA).

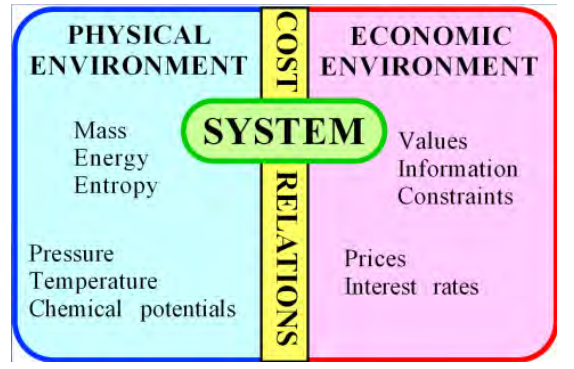

Fig. 8. The system surrounded by the physical and the economical environments, which are linked through cost relations.

Since exergy measures the physical value, and costs should only be assigned to commodities of value, exergy is thus a rational basis for assigning costs, both to the interactions that a physical system experiences with its surroundings and to the sources of inefficiency within it. The exergy input is shared between the product, and the losses, i.e. destruction and waste.

EEA simply means determining the exergy flows and assigning economic value to them. Thus, EEA does not include consideration of internal system effects. It does not describe how the capital investments in one part on the system affect exergy losses in other parts of the system. In the EEA method the exergy losses are numbers and not functions. However, this simple type of analysis sometimes gives ideas for, otherwise, not obvious improvements, and a good start of an optimization procedure, in which the exergy losses would be functions.

When constructing a system, the goal is often to attain the highest possible technical efficiency at the lowest cost, within the existing technical, economical and legal constrains. The analysis also includes different operating points (temperatures, pressures, etc.), configurations (components, flow charts, etc.), purpose (dual purpose, use of waste streams, etc.), and environments (global or local environment, new prices, etc.). Usually, the design and operation of systems have many solutions, sometimes an infinite number. By optimizing the total system, the best system under the given conditions is found. Some of the general engineering optimization methods could be applied, in order to optimize specific design and operation aspects of a system. However, selecting the best solution among the entire set requires engineering judgment, intuition and critical analysis. Exergy Economy Optimization (EEO) is a method that considers how the capital investments in one part of the system affect other parts of the system, thus optimizing the objective function. The marginal cost of exergy for all parts of the system may also be calculated to find where exergy improvements are best paid off.

\section{Final words}

These tools must be incorporated with energy engineering and policy to develop sustainable energy systems. My own experience from education is a strong positive feedback from the students and parts of the educational establishment, e.g., the UNESCO project Encyclopedia 
of Life Support Systems (EOLSS) [12]. However, sometimes there is also a strong skepticism among the academic establishment for this that also has to be dealt with. Thus, traditional boarders between different disciplines must be removed and more of interdisciplinary studies and activities must be applied at both high school and university levels. More problem oriented approaches and a focus on sustainable development issues are also to be encouraged.

\section{Conclusions}

Exergy based tools are excellent to describe the utilization of renewable energy resources and important within sustainable energy engineering. A system that consumes the exergy resources at a faster rate than they are renewed is not sustainable. The educational system has a crucial role to play to introduce these tools in order to promote education for sustainable development. This education must be based on a true understanding of our physical conditions. Exergy is a concept that offers a physical description of the life support systems as well as a better understanding of the use of energy and other resources in society. Thus, exergy and descriptions based on exergy are essential for our knowledge towards sustainable development.

\section{Acknowledgements}

The permission to use my work for the UNESCO's Encyclopedia of Life Support Systems [12] for this paper is hereby gratefully acknowledged.

\section{References}

[1] S. Carnot, Réflections sur la puisance motrice du feu et sur les machines propres a développer cette puissance, 1824, R. Fox, Paris, Bachelier, 1978.

[2] J.W. Gibbs, A Method of Geometrical Representation of the Thermodynamic Properties of Substances by Means of Surfaces, Trans. Conn. Acad, vol. II, 1873, pp. 382-404.

[3] Z. Rant, Exergie, ein neues Wort für 'technische Arbeitsfähigkeit'. (Exergy, a New Word for Technical Available Work), Forschungen im Ingenieurwesen, vol. 22, 1956, pp. 3637.

[4] M. Tribus, Thermostatics and Thermodynamics. New York: Van Nostrand, 1961.

[5] E. Sciubba, and G. Wall, A Brief Commented History of Exergy from the Beginnings to 2004, Int. J. of Thermodynamics, vol. 10, 2007, pp. 1-26.

[6] G. Wall, "Exergy - a Useful Concept within Resource Accounting”, Report No. 77-42, Institute of Theoretical Physics, Göteborg, 1977. http://www.exergy.se/ftp/paper1.pdf.

[7] G. Wall, "Exergy — a Useful Concept" Ph.D. thesis, Chalmers University of Technology, Göteborg, Sweden, 1986. http://www.exergy.se/ftp/thesis.pdf.

[8] The Exergoecological Portal, http://www.exergoecology.com.

[9] Szargut J, Morris D. Cumulative exergy consumption. Energy Research, vol. 11, 1987, pp. 245-61.

[10]M. Gong and G. Wall, "On Exergy and Sustainable Development - Part 2: Indicators and methods”, Exergy, an International Journal, vol. 1, 2001, pp. 217-233.

[11] Schleisner L. Life cycle assessment of a wind farm and related externalities. Renewable Energy, vol. 20, 2000, pp. 279-88.

[12]EOLSS, Encyclopedia of Life Support Systems. www.eolss.net. 